Article

\title{
Artificial Light at Night is Related to Broad-Scale Stopover Distributions of Nocturnally Migrating Landbirds along the Yucatan Peninsula, Mexico
}

\author{
Sergio A. Cabrera-Cruz ${ }^{1, *(D)}$, Emily B. Cohen ${ }^{2,+}{ }^{+}$Jaclyn A. Smolinsky ${ }^{1}$ and Jeffrey J. Buler ${ }^{1}$ (D) \\ 1 Department of Entomology and Wildlife Ecology, University of Delaware, Newark, DE 19713, USA; \\ jsmo@udel.edu (J.A.S.); jbuler@udel.edu (J.J.B.) \\ 2 Migratory Bird Center, Smithsonian Conservation Biology Institute, National Zoological Park, Washington, \\ DC 20013, USA; emily.cohen@umces.edu \\ * Correspondence: scabrera@udel.edu \\ + Current affiliation: Appalachian Laboratory, University of Maryland Center for Environmental Science, \\ Frostburg, MD 21532, USA.
}

Received: 1 December 2019; Accepted: 24 January 2020; Published: 26 January 2020

\begin{abstract}
The distributions of birds during migratory stopovers are influenced by a hierarchy of factors. For example, in temperate regions, migrants are concentrated near areas of bright artificial light at night (ALAN) and also the coastlines of large water bodies at broad spatial scales. However, less is known about what drives broad-scale stopover distributions in the tropics. We quantified seasonal densities of nocturnally migrating landbirds during spring and fall of 2011-2015, using two weather radars on the Yucatan peninsula, Mexico (Sabancuy and Cancun). We tested the influence of environmental predictors in explaining broad-scale bird stopover densities. We predicted higher densities in areas (1) closer to the coast in the fall and farther away in spring and (2) closer to bright ALAN and with lower ALAN intensity in both seasons. We found that birds were more concentrated near the coastline in the fall and away from it in spring around Cancun but not Sabancuy. Counter to our expectations, we detected increased bird densities with increased distance from lights in spring around Sabancuy, and in both seasons around Cancun, suggesting avoidance of bright areas during those seasons. This is the first evidence of broad-scale bird avoidance of bright areas during stopover.
\end{abstract}

Keywords: aeroecology; artificial light at night; stopover distribution; bird migration; Gulf of Mexico; light pollution; weather radar

\section{Introduction}

Nocturnally migrating birds travel long distances between their breeding and nonbreeding grounds, facing conditions along the way that could hinder or halt their journeys. For example, ecological barriers [1,2] and human alterations to the environment such as the addition of bright lights at night and wind turbines or other tall structures (e.g., communication towers [3]) are likely to influence the flight trajectories [4], altitudes [5,6], orientation and distributions of migrating birds [7]. Billions of Nearctic-Neotropical birds negotiate large bodies of water during migration including the Great Lakes, the western Atlantic Ocean, the Caribbean Sea, and the Gulf of Mexico (GOM) [8-12]. Food-rich coastal habitats are critical for migrating birds to fuel up before and after crossing such barriers. However, coastal ecosystems face increasing losses and degradation from human activities [13], potentially increasing the challenges that migrating birds may face.

Urban and rural settlements are responsible for light pollution that derives from the excessive use of artificial light at night (ALAN), making them identifiable through satellite imagery of the Earth $[14,15]$. Light pollution is a pervasive pollutant with multiple environmental effects [16-18] such 
as the disorientation and attraction of nocturnally migrating birds to bright ALAN, a phenomenon that we have known about for over a century [19]. ALAN has a wide range of effects on nocturnally migrating birds [20], and is increasingly recognized as a driver of their distributions. Bird stopover densities during migration at the landscape scale are unexpectedly high in urban areas [10,21], a result of broad-scale attraction of night migrants to ALAN [11,22]. This association is stronger during the fall migration season [22], possibly because juvenile birds are more prone to ALAN-related disorientation [23]. Furthermore, light pollution is a relatively novel stimulus during migration and is brighter and more ubiquitous along migration routes compared to relatively dark stationary breeding and non-breeding grounds [24]. Given the confluence of migrating birds around large water bodies where light pollution also occurs, bird distributions at temperate and sub-tropical latitudes are related not only to geographic and ecological factors [10,12], but also to light pollution [11].

The GOM is a marginal sea of the Atlantic Ocean with a maximum width of $\sim 1500 \mathrm{~km}$, bordered by $>4000 \mathrm{~km}$ of coastline. Two of the major migratory flyways in the Nearctic-Neotropical migration system converge in the GOM [25], and at least 2 billion birds navigate it every spring [26,27], with birds using the eastern flyway being more likely to fly across [25,28]. For example, Swainson's Thrushes (Catharus ustulatus), Wood Thrushes (Hylocichla mustelina), and Red-eyed Vireos (Vireo olivaceus) departing from coastal Alabama in fall arrive to the Yucatan Peninsula on average $22 \mathrm{~h}$ later [29]. Thus, the Yucatan Peninsula potentially constitutes the first landmass that some trans-gulf migrants reach in the fall after crossing the GOM on their way south, and the last they use before departing north in spring. Evidence from the northern GOM coast in the US indicates that migrating birds concentrate near the coastline in spring [30] after arriving energy-depleted from their trans-gulf flight [31]. However, in the fall, birds traveling south from breeding areas concentrate further inland in hardwood forests as they prepare for their southbound trans-gulf flight [30]. Furthermore, bird densities in the northern GOM are typically positively related to a larger proportion of forest cover [12,30,32]. Along the Atlantic coast of the US in the fall, birds concentrate near the coast presumably before making a trans-oceanic flight $[10,11]$. Moreover, along the Great Lakes in the US, birds concentrate near shorelines as they approach lakes and are less concentrated near shorelines on the far side of lakes after crossing [8]. Hence, the influence of habitat availability and distance from the coastline on stopover distributions is seasonally dependent in some geographies and not others. However, all of the available evidence about broad-scale distributions of migrating birds along the GOM coastlines comes from studies along the US coastline. This is the first effort at evaluating seasonal distributions of migrating birds on the southern tropical GOM coast in Mexico.

The coastal municipalities along the Mexican coast of the GOM lost 28.4\% of their original land cover between 1976 and 2000 [33]. Furthermore, the Yucatan Peninsula is among the coastal regions in Mexico with the greatest losses of natural land cover [33]. A large proportion of the beaches along the Peninsula's eastern coast need rehabilitation or restoration after environmental degradation mainly due to tourism developments and activities [34,35], and two of the three states in the Peninsula were among the Mexican territories with greater forest loss between 1993 and 2002 [36]. Neotropical migrants wintering on the Yucatan Peninsula use pristine habitats as well as areas with varying degrees of human alteration [37-39]. Although Neotropical migrants use urban green areas during migration throughout Latin America [40], they typically prefer large forest patches [41], which are expected to occur outside urban areas.

Here, we investigate the effect of light pollution, distance to the coast, and habitat on the seasonal distributions of nocturnally migrating birds on the coast of the Yucatan Peninsula in the southern GOM, using data from two weather radars located in the southwest (Sabancuy, Campeche) and northeast (Cancun, Quintana Roo) corners of the Yucatan Peninsula (Figure 1). Considering the stronger association of nocturnal migrants to light polluted areas at broad scales during the fall than in spring [22], we predicted that bird densities would be higher closer to bright areas, and this relationship would be stronger or more evident in the fall. However, at fine spatial scales, bird density should be lower in areas of brighter light [11]. Considering the degradation of the coasts around the 
Peninsula, we hypothesized that distance to the coast is an important predictor of bird distributions. Furthermore, given that migrating birds in the Peninsula are preparing for their trans-gulf flight in spring and recovering in fall, the opposite scenario as in the north GOM coast [30], it is possible that the seasonal relationship between stopover density and distance to coastline is reversed for the south GOM Mexican coast. Thus, we predicted that bird densities would be higher farther away from the coast in spring before migrating birds cross the GOM on their way north and higher close to the coast in the fall after crossing the Gulf on their way south, despite coastal degradation. Finally, we expected that land cover, forests in particular, would have an important effect on bird densities, as many migrating birds are forest-associated species and rely on forested habitat for resting and refueling [32]. This work complements the considerable body of literature on the seasonal movements of migrating birds through the northern coast of the GOM [42] including the factors governing their stopover distributions, and increases our understanding of the global influence of light pollution on migrating birds. This is also the first study to compare the relationship of bird distributions to light pollution among spring and fall seasons using weather surveillance radar data.

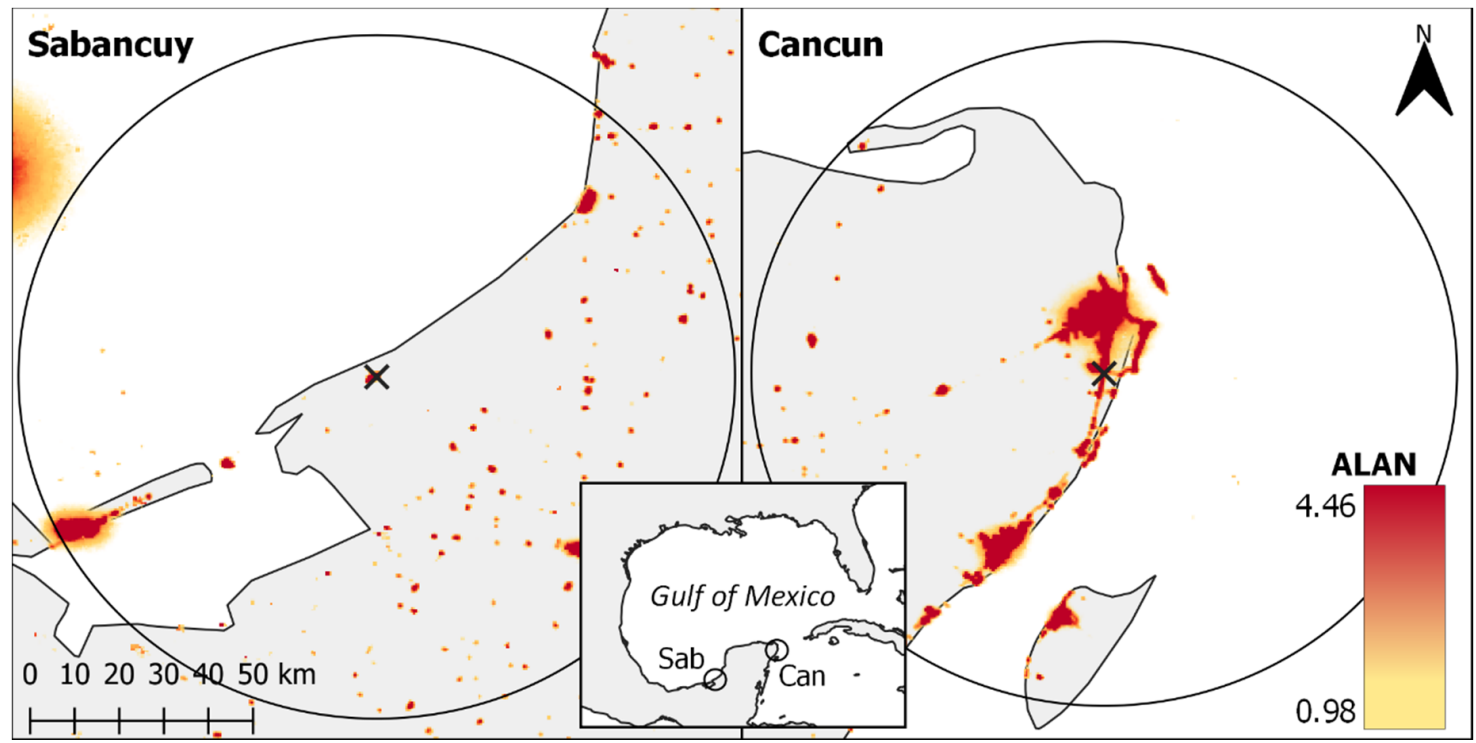

Figure 1. Location (black crosses) and $80 \mathrm{~km}$ detection range (black circles) of the Sabancuy (Sab) and Cancun (Can) weather radars in the Yucatan Peninsula showing the average intensity of artificial light at night (ALAN) during spring and fall migration of 2012 (https://ngdc.noaa.gov/eog/viirs/download_ dnb_composites.html). Central inset shows the location of the radars in relation to the Gulf of Mexico. Scale bar of ALAN intensity is common to both figure panels and is based on radiance values around Cancun expressed in units of nanoWatts per square centimeter per steradian ( $\left.\mathrm{nW} \mathrm{cm}{ }^{2} \mathrm{sr}\right)$.

\section{Materials and Methods}

\subsection{Radar Data and Processing}

We sampled the distributions of birds taking off from terrestrial stopover sites for nocturnal migration (i.e., evening migration exodus) during the spring (01 March-30 May) and fall (15 Aug-15 Nov) migration seasons of 2011-2015, using data from two weather surveillance radars (Sabancuy and Cancun) located on the Yucatan Peninsula in the southern GOM (Figure 1). Sampling the atmosphere at the onset of bird migration with weather radar provides quantitative measures of bird densities at the ground during migratory stopover [43]. We obtained all available data for dates within our defined migration periods from Mexico's National Water Commission.

The Sabancuy and Cancun weather surveillance radars are Doppler C-band units that observe the weather inland and off the coast, while also detecting echoes from flying animals. These radars emit bursts of single-polarized electromagnetic energy through a rotating antenna, measuring the amount of 
energy reflected back from scattering meteorological and biological bodies (i.e., radar reflectivity factor), which provides a measure of the volumetric density of scatterers in the air around the radar unit [44]. The radars sample the airspace via a volume scan taken every $15 \mathrm{~min}$. A volume scan consists of multiple $360^{\circ}$ sweeps of the atmosphere at a different number of tilt angles ranging from $0.5^{\circ}$ to $20^{\circ}$ depending on the radar coverage pattern. Radars measure and store reflectivity and other measures, such as Radial velocity, for individual sampling volumes within each sweep of a volume scan. The sampling volumes have boundaries corresponding to the polar spatial resolution of $200 \mathrm{~m} \times 1^{\circ}$ (Sabancuy) and $250 \mathrm{~m} \times 0.5^{\circ}$ (Cancun). We used the Weather Decision Support System-Integrated Information software [45] to convert radar files from their native format to other data formats for processing.

The onset of nocturnal bird migration is a highly synchronized mass movement of migrating individuals in response to sun elevation. Birds typically start their exodus from terrestrial stopover sites when the sun is $\sim 6^{\circ}$ below the horizon [46] or $\sim 30-45$ min after sunset. Bird migration exodus looks like sudden blooms of reflectivity centered around the radar (e.g., Video S1), as birds enter the airspace sampled by the radar [47]. We used UNIDATA's Integrated Data Viewer [48] to visually screen radar sweeps from the $0.5^{\circ}$ tilt angle (i.e., the lowest elevation angle) around the onset of migration exodus within a $100 \mathrm{~km}$ range from the radar. We considered precipitation as an indication of adverse weather during the rest of the night, and since precipitation at dusk typically results in low bird migration intensity [49], we excluded nights when precipitation occurred within $50 \mathrm{~km}$ from the radar (see below), or when precipitation contaminated reflectivity blooms of bird exodus. We also excluded nights when anomalous radar beam propagation occurred, since this condition implies that the radar beam curves towards the ground in an unpredictable way due to certain atmospheric conditions [44], contaminating the data with ground returns. The Sabancuy and Cancun radars provide reflectivity measures of migrating birds at exodus within a limited range $(<50 \mathrm{~km})$, or with gaps within the radar coverage area (i.e., not all radar sample volumes contain data, see Figure S1). Radial velocity measures were too sparse to determine airspeeds of flying animals and we thus were unable to conduct analysis to discriminate sampled nights as insect- or bird-dominated (sensu [10]). However, Radial velocity standard deviation $>2 \mathrm{~m} \mathrm{~s}^{-1}$ is indicative of bird presence in C-band radar data [50]. Hence, as an alternative method to discriminate bird-from insect-dominated nights, we estimated the Radial velocity standard deviation of over-land sample volumes of $\sim 6$ radar sweeps around time of exodus for each night considered for analysis. The range of nightly average Radial velocity standard deviations for Sabancuy was 3.15-4.59 in spring and 3.38-10.81 in the fall. Only one night in Cancun had an average Radial velocity standard deviation of 1.75; otherwise, the ranges were 2.06-2.4 in spring and 2.22-2.42 in the fall. Thus, we feel confident that the great majority of the data used for analyses had presence of migrating birds. As an additional conservative measure, we retained for analysis only nights with blooms of reflectivity around the expected exodus time [47] and assumed that these were bird-dominated because bird reflectivity typically obscures insects' [51].

For selected sampling nights, we spatio-temporally interpolated reflectivity measures to the sun elevation at either "peak" exodus (the instant of greatest rate of increase in reflectivity during migratory exodus) or $15 \mathrm{~min}$ after the onset of exodus, whichever occurred first $[10,11,47]$. This allowed us to obtain a single snapshot of birds aloft at the same relative point of migration exodus before they dispersed too far away from their ground sources.

Radar reflectivity measures are subject to range bias: a decline in reflectivity values with distance from the radar as the radar beam increases in altitude and overshoots scatterers $[43,44,47]$, which hampers the comparison of reflectivity measures across the radar domain. We minimized range bias by estimating the Vertically Integrated Reflectivity (VIR), an equivalent measure of reflectivity with respect to a common height reference across ranges [47]. For this, we estimated the height limits of the radar beam and a seasonal mean vertical profile of reflectivity at peak exodus for each radar. The vertical profiles represent how radar reflectivity of birds aloft varies with height above the ground [52]. We derived vertical profiles by integrating reflectivity data from the five lowest radar tilts for $10 \mathrm{~m}$ height intervals in relation to the mean reflectivity in the total airspace sampled 
by the radar to a common height reference (0 to $1750 \mathrm{~m}$ above the ground level) [43]. Because our data did not contain reflectivity data for all tilts for all sampling nights or years, for Sabancuy we estimated a single representative seasonal mean vertical profile using a subset of sampling nights with comprehensive volume scans ( $\mathrm{n}=11$ and 13 for 2014 and 2015 respectively). For Cancun, we were able to estimate only one representative mean vertical profile using 9 nights of data. We estimated radar beam limits of every sampling volume by modeling beam propagation paths assuming standard atmospheric refraction. For each sampling volume, we divided the interpolated reflectivity at exodus by the mean vertical profile ratio within the sampling volume's beam limits, to obtain a volumetric measure of mean bird density integrated within the reference height (i.e., volumetric VIR) in units of $\mathrm{cm}^{2}$ per $\mathrm{km}^{3}$. We then "flattened" VIR of birds aloft to the ground by dividing volumetric VIR by the height reference $(1750 \mathrm{~m})$ to derive a VIR estimate in units $\mathrm{of}_{\mathrm{cm}}^{2}$ per ha ${ }^{-1}$, representing the total cross-sectional area of birds in the air above a one hectare area on the ground [11,47]. For both radars, the effective detection range was where the vertical profile of reflectivity ratio for the range correction was greater than 0.05 . We summarized VIR for each sample volume by pooling radar data across days and years and calculating the geometric mean of VIR as a relative measure of the mean daily density of birds during migration exodus.

For all analysis, we used radar data located between $7.5 \mathrm{~km}$ and up to the maximum range with data from potentially biological scatters. We set the lower range limit because the radar beam in the first kilometers from the radars is too narrow to produce reliable data [53]. Additionally, we excluded radar volume samples (1) located off the coast and where the proportion of water estimated from our land cover data set (see below) was $>0.75$, (2) where the radar beam is blocked at least $25 \%$ by topographical or human-made features, and (3) dominated by persistent ground-clutter that contaminates reflectivity measures [10,47]. From the radar data, we identified multiple known bat roosts $\sim 50-60 \mathrm{~km}$ southeast of the Sabancuy radar (Cú-Vizcarra, pers. comm.) that became active approximately around sunset, sometimes overlapping with bird migration exodus. Hence, to prevent data contamination from bats, we removed all sample volumes located between 47,100 $\mathrm{m}$ and 76,000 $\mathrm{m}$ from the radar within an arc between $103^{\circ}$ and $137^{\circ}$. We did not identify any roosts around the Cancun radar.

\subsection{Model Covariates}

We created polar polygon grids for each radar. Each polar grid consists of polygons radiating around the radar location up to a distance of $100 \mathrm{~km}$, with polygons having depths and widths of $200 \mathrm{~m}$ $\times 1^{\circ}$ (Sabancuy) and $250 \mathrm{~m} \times 0.5^{\circ}$ (Cancun). Each polygon corresponds to the Cartesian boundary of every radar sample volume at the $0.5^{\circ}$ tilt angle. We overlaid our polar polygon grids on geospatial data and extracted measures of 17 different environmental variables expected to affect bird stopover density to each radar sample volume (Table 1). We used these environmental variables as covariates in our models to explain variability in bird stopover densities.

To estimate light pollution related variables, we used the $\mathrm{R}$ package 'Rnightlights' [54] to download monthly cloudless satellite composite images of the earth at night from the US National Oceanic and Atmospheric Administration free data repositories. These images are composited from imagery originally collected by the Visible/Infrared Imager/Radiometer Suite of the Suomi National Polar-orbiting Partnership satellite, collecting measures of night light radiance in units of nanoWatts per square centimeter per steradian $\left(\mathrm{nW} \mathrm{cm}^{2} \mathrm{sr}\right)$. Night lights radiance vary seasonally, especially in areas with seasonal changes in land cover properties such as snow cover and vegetation [55]. Although we do not expect significant seasonal changes in land cover in our tropical study area, we downloaded available night-light images for the bird migration months of 2012 (April-May, and Sep-Nov), and averaged them to obtain a single night-light dataset during bird migration months only. Since night-light data are right skewed, we log10-transformed the averaged radiance, adding 0.001 first to improve data distribution (Figure S2). We then estimated the average night light intensity for each radar sample volume of each radar. Finally, we identified "bright areas", defined as areas where night-light radiance is $\geq 26$, approximately equivalent to a sky brightness at the zenith five times 
greater than natural light brightness, the level of night sky brightness where the Milky Way is no longer visible to the human eye [56]. This is the threshold brightness that produces the strongest relationship between bird stopover distribution and distance to bright light [11]. We then estimated the Euclidean distance of each radar sample volume to bright areas. Similarly, we used a geospatial product of the coastlines of the world to estimate the Euclidean distance from each radar sample volume to the coast.

Table 1. Names and descriptions of model covariates.

\begin{tabular}{|c|c|}
\hline Name & Description (units) \\
\hline \multicolumn{2}{|l|}{ Light pollution } \\
\hline Distance to bright lights & $\begin{array}{c}\text { Distance of radar sample volumes to areas with bright artificial } \\
\text { lights at night }(\mathrm{m})\end{array}$ \\
\hline Mean ALAN intensity & $\begin{array}{l}\text { Average intensity of Artificial Lights at Night during migration } \\
\text { months of year } 2012\left(\log _{10}+0.001 \mathrm{nW} \mathrm{cm}^{2} \mathrm{sr}\right)\end{array}$ \\
\hline \multicolumn{2}{|r|}{ 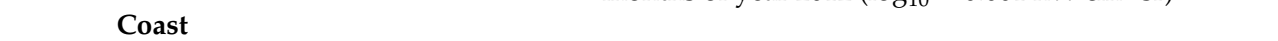 } \\
\hline $\begin{array}{l}\text { Distance to coast } \\
\text { Land cover }\end{array}$ & Distance of radar sample volumes to GOM coastline (m) \\
\hline Evergreen forest & Proportion of evergreen forest within radar sample volumes \\
\hline Deciduous forest & Proportion of deciduous forest within radar sample volumes \\
\hline Mixed forest & Proportion of mixed forest within radar sample volumes \\
\hline Shrubland & Proportion of shrubland forest within radar sample volumes \\
\hline Grassland & Proportion of grassland within radar sample volumes \\
\hline Barren & Proportion of barren lands within radar sample volumes \\
\hline Wetland & Proportion of wetland within radar sample volumes \\
\hline Cropland & Proportion of cropland forest within radar sample volumes \\
\hline Urban & Proportion of urban forest within radar sample volumes \\
\hline Water & Proportion of water cover within radar sample volumes \\
\hline Unspecified non-forest & $\begin{array}{c}\text { Proportion of unspecified land cover in areas of recent forest loss } \\
\text { within radar sample volumes }\end{array}$ \\
\hline Mean NDVI & $\begin{array}{l}\text { Mean seasonal Normalized Difference Vegetation Index within } \\
\text { radar sample volumes }\end{array}$ \\
\hline \multicolumn{2}{|l|}{ Corrective } \\
\hline Distance to radar & Distance of radar sample volumes to radar $(\mathrm{m})$ \\
\hline Relative elevation & Difference between radar antenna height and ground height $(\mathrm{m})$ \\
\hline
\end{tabular}

We considered habitat availability by including 10 land cover variables, a measure of forest loss, and a measure of vegetation greenness, the Normalized Difference Vegetation Index (NDVI). The North American Land Change Monitoring System is a 30m resolution land cover dataset identifying 19 land-cover types consistently for Mexico, the US, and Canada, based on 2010 satellite imagery [57]. We reclassified this dataset from 19 to 10 more generalized categories (Table S1). Unfortunately, during the course of the study we discovered that recent deforestation processes in the Yucatan Peninsula [58] are not reflected in this dataset. Hence, we used version 1.6 of the Global Forest Change dataset [59] to update [57] by identifying areas that lost forest cover since 2000 to the most recent year for which we had suitable nights for each radar and season. Thus, we effectively created a new land cover category that we call 'Unspecified non-forest' since we do not know the land cover type established after deforestation occurred. We then estimated the proportion of land cover within each radar sample volume. We also included a measure of vegetation greenness because it relates positively with bird densities at stopover [11]. We used the R package 'MODIS' [60] to download the NDVI from the MYD13Q1 Vegetation Indices product from the USGS Land Processes Distributed Active Archive Center for the periods within spring and fall migrations for which we had suitable nights. We estimated NDVI values at the centroid of each radar sample volume for each suitable night, matching the date to the closest-in-time NDVI measure, which are generated biweekly. We then estimated a seasonal average, obtaining a mean NDVI value from dates used for analyses.

We also included two corrective variables. Although we made an attempt to reduce range bias when processing radar data, we included distance to radar and relative elevation as predictors in the stopover density models to control for any residual measurement error due to range bias [43]. 
We estimated relative elevation as the difference between radar antenna height and ground height, so that positive values indicate terrain heights below the antenna.

\subsection{Model Analysis}

We used the gradient boosting method of Boosted Regression Trees to model the log10-transformed geometric mean of the VIR separately by radar and season as a function of all the predictor variables (i.e., proportion of land cover classes, distance to bright lights, mean ALAN intensity, and distance to coast). Boosted Regression Trees is a statistical method that combines regression trees and boosting algorithms, ultimately fitting a single model in a forward, stagewise way [61]. The Boosted Regression Tree models (models, hereafter) do not make assumptions about the data distribution of the response variable. Hence, it can fit non-linear response functions; in addition, it automatically models interactions among predictors [61]. Detailed accounts of the method and its application in ecology are available in [61,62]. Modeling was performed in R [63] with the library 'dismo' and function 'gbm.step', which optimizes the fit of the model through cross validation [64]. We used a tree complexity of 2 to allow only two-way interactions among predictors, bag fraction of 0.5 , a Gaussian error distribution, and a learning rate varying by radar and season to produce a minimum of 1000 trees in the optimized model. The learning rate weighted the contribution of each tree to the model, and the bag fraction specified the proportion of data used to train the model [61]. We used the 'gbm.interactions' function from the R package 'dismo' to identify important two-way interactions between predictors. The analysis ranks predictor variables by their relative influence explaining the response, as a measure of how many times each variable was selected for splitting trees [61]. In order to consider only biologically relevant predictors in our interpretations, we re-casted the importance of each predictor after excluding the influence of variables controlling for measurement error (i.e., distance to radar and relative elevation).

In ecology, variable correlation is typically considered high when $r>|0.7|$ [65]. However, analytical methods similar to ours can identify the relationship of highly correlated predictors to the response when large sample sizes are used [11]. We tested for correlation among all predictors with a Pearson's correlation test and dropped those with $r>|0.8|$, except when correlation was with relative elevation or with distance to radar. For Sabancuy, we removed proportion of grassland as predictor in spring because it was negatively correlated with proportion of wetland ( $r=-0.88$; Figure S3). Distance to bright lights was correlated to distance to radar in the fall season at the Sabancuy radar $(\mathrm{r}=-0.83)$. However, our models included $\sim 6000-\sim 30,000$ observations/radar (i.e., radar sample volumes), and the inclusion of these correlated variables in the models did not change the direction of any relationship nor the ranking of the relative importance of the predictors explaining the response.

\section{Results}

We had access to spring and fall data of 2011-2015, but no usable data were available for 2013. Data were sparsely archived by radar and year. Hence, the number of dates with data differ by radar. In spring and fall, we sampled migratory bird exodus for 58 and 39 radar nights across years respectively, with a range of 17-23 nights in spring and 8-15 nights in the fall (Table 2). There was little overlap among radars in the years and seasons that provided suitable sampling nights. Thus, within-year comparisons of bird densities between radars was not feasible. In total, $\sim 15.5 \%$ of all available radar nights $(\mathrm{n}=626)$ provided suitable samples. The main reasons for discarding nights included precipitation ( $\sim 60 \%)$ and missing data $(\sim 20 \%$, see discussion); anomalous beam propagation, clutter, and sea breezes were responsible for $\sim 3 \%$ of excluded data. 
Table 2. Number of nights used for analysis by radar, season, and year.

\begin{tabular}{ccccc}
\hline & \multicolumn{2}{c}{ Sabancuy } & \multicolumn{2}{c}{ Cancun } \\
\hline Year & Spring & Autumn & Spring & Autumn \\
\hline 2011 & & 15 & & \\
2012 & & & 17 & 8 \\
2014 & 23 & 8 & & \\
2015 & 18 & 8 & & 8 \\
\hline Total & 41 & 31 & 17 & \\
\hline
\end{tabular}

The Boosted Regression Trees models identified that the two broad-scale predictors, distance to the coast and distance to bright lights, were consistently the top two biologically relevant predictors of bird stopover densities across radars and seasons (Table 3). Other finer-scale predictors that ranked high included ALAN intensity, NDVI, proportion of water (for Cancun only), wetland, and unspecified non-forest (for Sabancuy, only in spring). The cumulative relative influence of the top five predictors at explaining bird densities ranged between $86.54 \%$ and $90.33 \%$ across radars and seasons. Local landscape composition variables (i.e., proportions of land covers within sampling volumes) were consistently among the weakest predictors of bird densities. The relative influence of all predictors included in the analysis is available in Table S2 of the Supplementary Materials. The cross-validation correlation, a goodness-of-fit measure for models, ranged between 0.47 and 0.86 across radars and seasons. The seasonal distribution of bird densities around each radar in relation to lights is shown in Figure S1.

Table 3. Relative variable influence of biological predictors (i.e., excluding distance to radar and relative elevation) of bird stopover densities from the Boosted Regression Tree models by radar and season, and sum of the top five predictors, indicated in bold font. Also shown are the mean \pm standard error (SE) of cross-validation correlations for each model.

\begin{tabular}{ccccc}
\hline \multirow{2}{*}{ Predictor } & \multicolumn{2}{c}{ Sabancuy } & \multicolumn{2}{c}{ Cancun } \\
\cline { 2 - 5 } & Spring & Autumn & Spring & Autumn \\
\hline Light pollution & & & & \\
Distance to bright lights & $\mathbf{2 3 . 7 3}$ & $\mathbf{2 7 . 1 5}$ & $\mathbf{2 1 . 3 4}$ & $\mathbf{2 4 . 1 8}$ \\
Mean ALAN intensity & $\mathbf{1 2 . 8 3}$ & $\mathbf{1 3 . 6 6}$ & $\mathbf{1 9 . 6 7}$ & $\mathbf{1 7 . 8 1}$ \\
Coast & & & & \\
Distance to coast & $\mathbf{3 5 . 6 9}$ & $\mathbf{2 1 . 3 7}$ & $\mathbf{3 0 . 1 2}$ & $\mathbf{2 6 . 7 5}$ \\
Land cover & & & & \\
Evergreen forest & 2.34 & 3.75 & 4.60 & 0.45 \\
Deciduous forest & - & 0.00 & 0.06 & 0.06 \\
Mixed forest & - & - & - & - \\
Shrubland & - & - & 0.00 & 0.00 \\
Grassland & - & 4.00 & 0.05 & 0.01 \\
Barren & 0.00 & 0.93 & 0.07 & 0.12 \\
Wetland & 5.20 & $\mathbf{9 . 5 0}$ & $\mathbf{4 . 7 6}$ & 3.51 \\
Cropland & 0.00 & 0.15 & - & - \\
Urban & 1.58 & 0.87 & 2.01 & 5.43 \\
Water & 0.55 & 0.83 & $\mathbf{1 2 . 7 0}$ & $\mathbf{1 2 . 4 4}$ \\
Unspecified non-forest & $\mathbf{5 . 3 2}$ & 2.93 & 0.49 & 1.55 \\
Mean NDVI & $\mathbf{1 2 . 7 6}$ & $\mathbf{1 4 . 8 7}$ & 4.12 & $\mathbf{7 . 7 0}$ \\
Sum & 90.33 & 86.54 & 88.59 & 88.87 \\
SE cross-validation & $0.53 \pm 0.00$ & $0.56 \pm 0.00$ & $0.86 \pm 0.01$ & $0.47 \pm 0.01$ \\
correlation & & & & \\
\hline
\end{tabular}

According to our prediction, bird densities closest to bright lights were relatively higher in the fall than in spring for both radars (Figure 2). Bird densities around Sabancuy had generally opposite responses in spring compared to fall. However, despite the relatively higher density of birds $<3 \mathrm{~km}$ from bright lights in fall compared to spring around Cancun, relative bird densities for both seasons 
peaked at the farthest distance from the bright lights sampled (i.e., $\sim 25 \mathrm{~km}$ in spring and $18 \mathrm{~km}$ in the fall). Thus, opposite to what we expected we detected an increase in bird densities with distance from lights in spring around Sabancuy, and in both seasons around Cancun, suggesting avoidance of bright areas during those seasons.

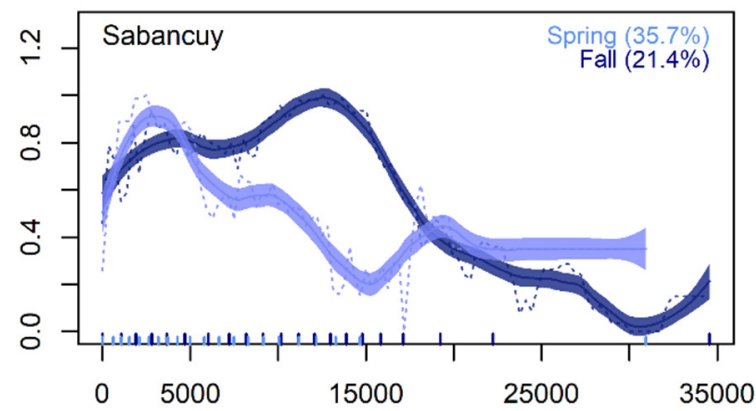

Distance to coast $(\mathrm{m})$

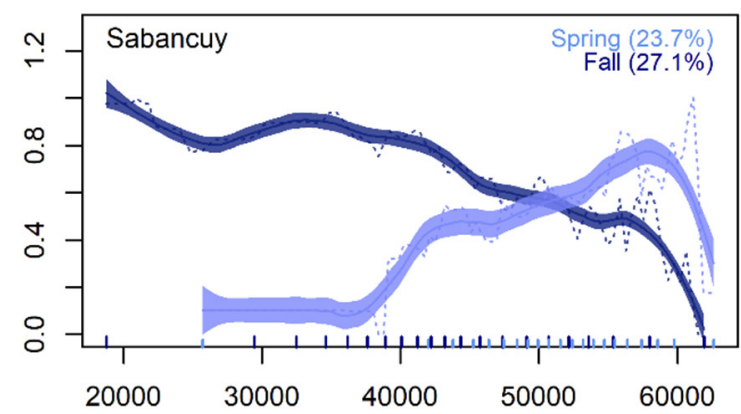

Distance to bright lights $(\mathrm{m})$

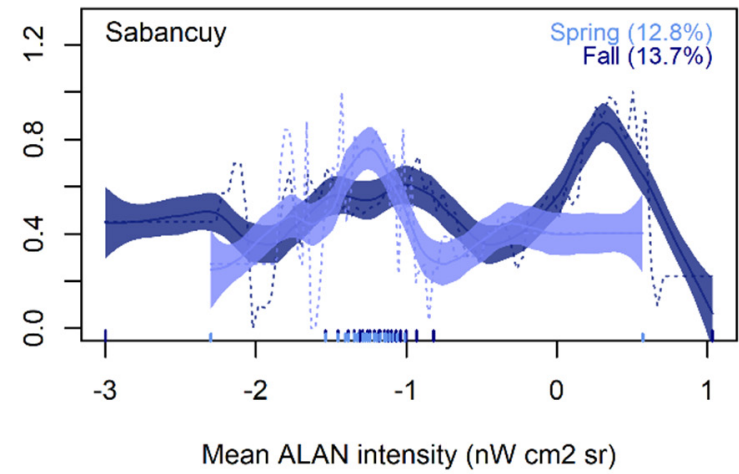

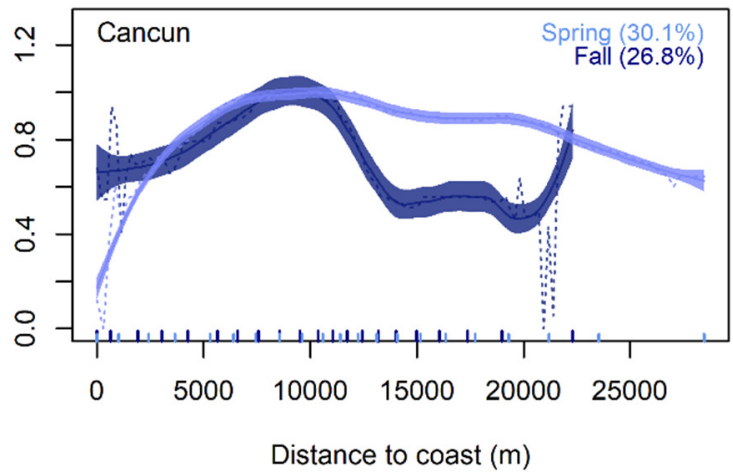

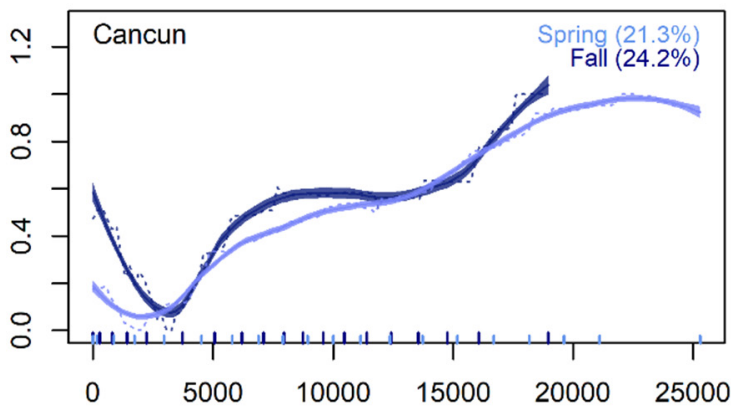

Distance to bright lights $(m)$

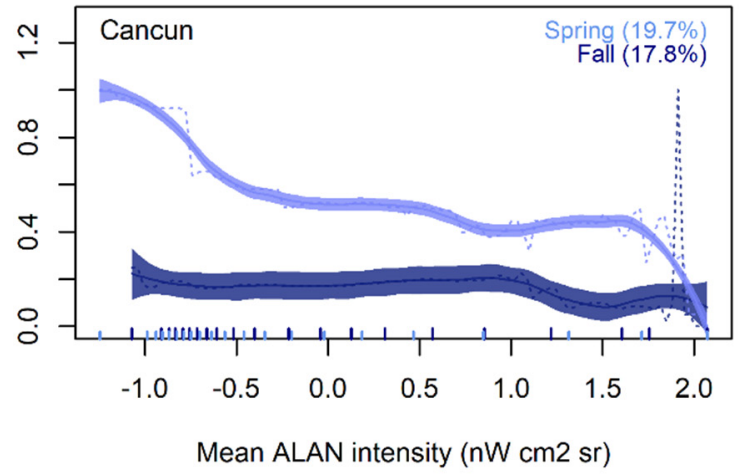

Figure 2. Partial dependency plots of distance to coast, distance to bright lights, and mean intensity of artificial lights at night (ALAN) in relation to bird densities around the Sabancuy and Cancun weather radars in the southern Gulf of Mexico in spring and fall migration seasons. Solid lines and thick curves are the mean $\pm 95 \%$ CI of the smoothed original trend line from the Boosted Regression Tree models, shown as dotted lines. Numbers in parenthesis show the relative importance of the predictor for each season after removing non-biologically important predictors. Y-axis represent a measure of bird densities around radars scaled from zero to one for easy comparison of the relationships. X-axis of mean ALAN intensity is $\log _{10}$-transformed. Rug plots on the $x$-axis show deciles of the distribution of predictor values for each radar. Plots of all other predictors included in models for each radar and season are available in Figures S4 to S7. Color version of figure is available online.

Counter to our prediction, the relative peak in bird stopover densities with respect to distance to the coast around the Sabancuy radar in spring occurred closer to the coast in spring (within $5 \mathrm{~km}$ 
from the coast) than in the fall (at $13 \mathrm{~km}$ from the coast; Figure 2). Furthermore, high bird densities during the fall were spread out within $15 \mathrm{~km}$ from the coastline. This is the distance at which spring densities drop to a relative minimum, indicating higher concentrations near the coast in spring even though bird densities at the coast are similar in both seasons. According to our prediction, however, bird densities were relatively more concentrated near the coastline around the Cancun radar in the fall than in spring (Figure 2). Specifically, although the peak bird densities around this radar occurred at $\sim 10 \mathrm{~km}$ from the coastline in both seasons, they rapidly dropped at a distance of $\sim 15 \mathrm{~km}$ in the fall, while they remained comparatively higher in spring, indicating an overall higher concentration of birds near the coastline in the fall.

Local-scale factors were less influential in general and we highlight a few of the relatively more influential. For Sabancuy bird densities increased with increasing mean NDVI, with a higher importance in the fall (Figures S4 and S5). For Cancun, bird density generally declined with greater proportion of water (Figures S6 and S7). Interestingly, spring bird densities around Sabancuy were relatively high in relation to low and high proportions of unspecified non-forest, but low with moderate proportions; in the fall, bird densities around Sabancuy were relatively high in relation to low and mid proportions of wetland (Figure S5). For Cancun, bird density reached maximum relative density at mid and high proportions of wetland.

With regards to fine-scale response to local light intensity, we found a negative relationship between bird density and ALAN intensity around Cancun during spring, but not during fall. Instead, bird densities during the fall were relatively constant throughout all light pollution levels around Cancun. The relationship between bird densities and mean ALAN intensity around Sabancuy was noisy, with no clear positive or negative trend. The strongest interactions in the models of bird densities around the Sabancuy radar were between distance to the coast and distance to bright lights, in both seasons. In spring, bird densities were highest closer to the coast and farther from bright lights. The opposite pattern occurred during fall migration when densities were higher farther away from the coast and closer to bright lights (Figure 3). For the Cancun radar, the interaction between distance to coast and bright lights was the least important in spring, but the most important in the fall (Table S3). In spring, bird densities were lowest at the coastline regardless of distance to bright lights but peaked between 5 and $10 \mathrm{~km}$ from the coast while also increasing with distance to lights (Figure 3). In the fall, bird densities were highest at the coastline, particularly closer to bright lights, but beyond the coastline they were consistently low near bright lights, increasing with distance to lights. The most important interaction in spring around Cancun was between proportion of water and distance to bright lights, with greater bird densities related to higher proportions of water regardless of distance to lights, and to short distances to bright lights regardless of proportion of water (Figure S8). The relative importance of all identified interactions is provided in Table S3. 

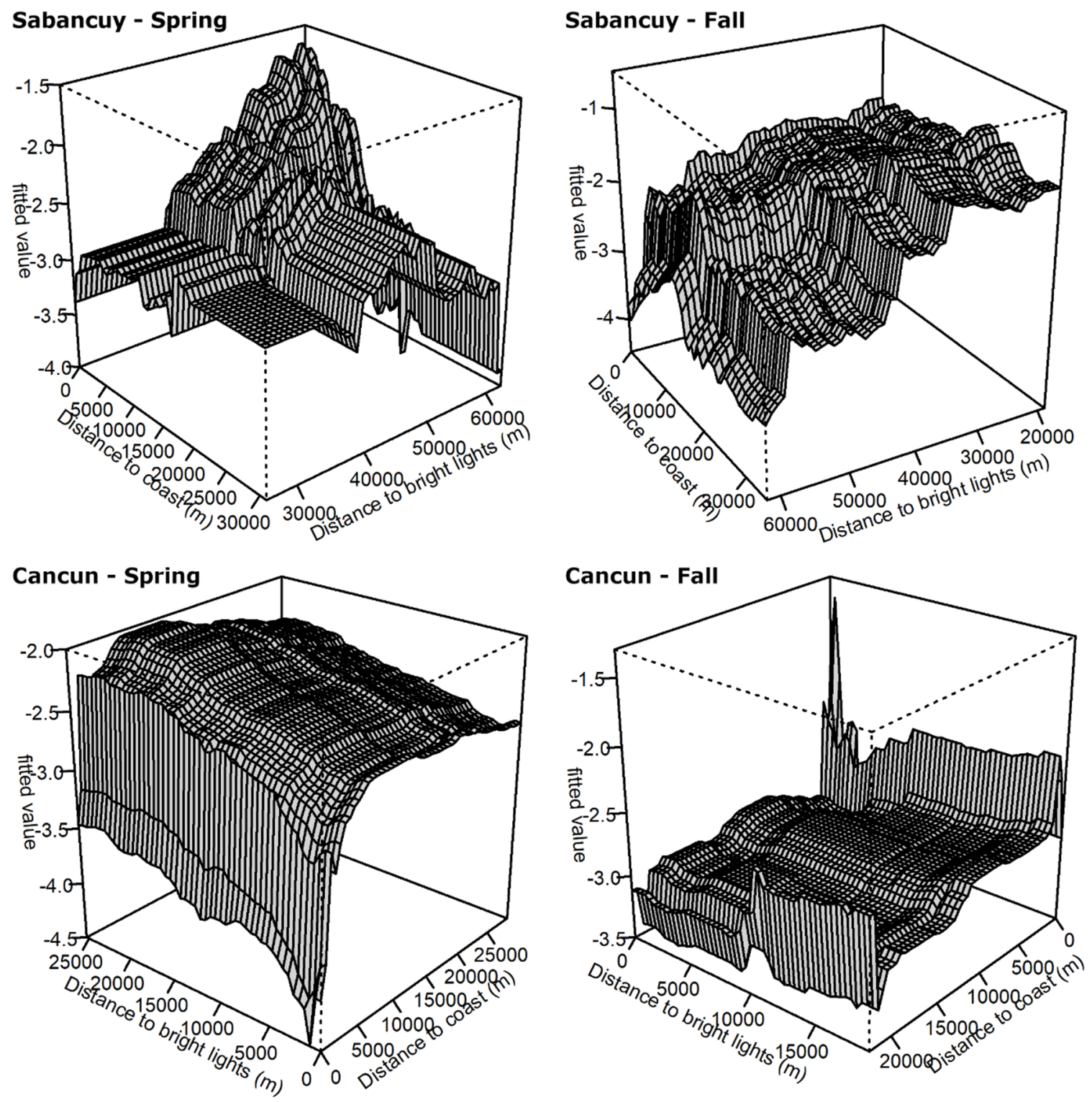

Figure 3. Partial dependency plots for the interaction between distance to the coast and distance to bright lights, from Boosted Regression Tree models of bird densities during migration exodus around two weather radars (Sabancuy and Cancun) located in the Yucatan Peninsula, in spring and fall migration seasons.

\section{Discussion}

Broad-scale geographic positions relative to artificial lights and the coast were more important than fine-scale land cover composition in influencing the distribution of nocturnally migrating birds during their diurnal stopovers on the Yucatan Peninsula, Mexico. This is consistent with the nature of spatial scaling in the hierarchical process of stopover habitat selection in birds [32,66], which narrows down from the broadest geographical scale in which birds migrate through, to the finest scale in which they make the final selection $[32,66,67]$. Thus, factors from broad to fine scale have a differential influence on bird distributions, but landscape-scale features seem to drive broad-scale distributions [32]. For example, geographic position such as distance to the coast has a dominating effect on explaining bird distributions at a broad landscape scale [10], including in the northern GOM coast [12]. Thus, our results corroborate the dominance of landscape-scale factors in the distributions of migrating 
birds, and support the scale-dependency of habitat selection around the GOM, including the northern Yucatan Peninsula [68]. However, our results also contradict previous findings in part regarding the broad-scale attraction of nocturnal migrants to bright urban areas, as we found evidence of avoidance of light pollution.

There is consistent evidence of broad-scale attraction of migrating birds to the bright lights of urban areas in the US [11] during both spring and fall [22]. The attraction to lights is stronger during the fall migration season [22], when juvenile birds migrate for the first time and are prone to greater disorientation due to light pollution [23]. Thus, it is expected that bird densities are higher closer to bright urban areas during the fall. Our results extend this general phenomenon to migrants seeking stopover habitats in tropical America during fall. However, contrary to past studies, our results also suggest avoidance of bright lights in spring, when we found higher bird densities in relation to distances far away from lights around both radars. Admittedly, we could not sample the distances closest to bright lights around Sabancuy, but bird densities at the shorter distances sampled are the lowest, increasing thereafter. Furthermore, bird densities around Cancun drop to a minimum 2-3 km from bright lights in both seasons, and then increase consistently throughout the whole range of distances sampled, indicating relatively high bird densities closest to bright areas, but much higher away from them. Additionally, bird density declined with greater intensity of artificial lights at a fine spatial scale in spring. To our knowledge, this is the first radar analysis of broad-scale bird migration in relation to ALAN during spring, and we provide evidence counter to that from citizen-science-based observations in the US, which indicates attraction to bright areas during both migration seasons [22]. Considering the greater attraction of migrating birds to ALAN and urban areas in the fall $[22,23]$, and that greater mortality due to anthropogenic causes concentrates in the same season [69], we hypothesize that anthropogenic-related bird mortality during the fall selects for individuals with low attraction to ALAN. Thus, we propose that naïve and ALAN-attracted individuals are selected out during their southwards migration in the fall, while a higher proportion of experienced or ALAN-resistant individuals return north, resulting in the observed avoidance of ALAN in spring, potentially explaining the lower number of bird collisions with lit buildings in spring [70].

Alternatively, higher bird densities away from bright lights around coastlines of the southern GOM in spring, when birds are heading north back to their breeding sites, may be related to birds selecting the best available habitat to refuel before embarking on a long barrier-crossing flight. Migratory birds preparing for long distance flights require food-rich habitat for refueling, as their fuel load heavily influences their migratory performance [71]. Some species or individuals prefer to stopover in the largest forest patches available [41]. Thus, when preparing for a long-distance flight, migrating birds may concentrate away from urban light-polluted areas, which presumably offer less vegetated cover compared to larger patches of forests available outside of densely human populated areas. If this were true, we would expect avoidance of bright lights in the fall around the northern GOM coast, before migrants embarked on southbound flights across the GOM towards their wintering sites. An analysis of the influence of ALAN on bird distributions along the northern GOM could test this hypothesis.

The attraction of birds to bright urban areas reported by McLaren et al. [11] is based on the highly urbanized and light-polluted northeastern US region. Our results relate to bird densities around urban areas with similar degrees of light pollution as elsewhere in North America [56], but they are certainly smaller in extent, particularly around the Sabancuy radar, where rural areas dominate. Hence, the question arises of whether the evidence of avoidance that we found might be related to the smaller extent of individual bright areas compared to those in North America, rather than to a seasonal effect. The only evidence of broad-scale attraction to lights in spring comes from a study that used bird occurrences at a very large-scale [22], incorporating light pollution data from the largest to the smallest human settlements from North to Central America. Hence, the potential avoidance of small urban areas might have been masked by attraction to large bright areas. However, other studies have found weaker association of migrating birds to urban areas in spring and stronger during the fall [21], 
consistent with [22], and observational studies confirm that migrating birds use urban areas during both seasons in North America and Latin America [40,41]. Nevertheless, we observed evidence of avoidance not only around Sabancuy but also around Cancun, where the largest bright areas within our study areas occur and where bird densities were highest away from lights in both seasons. Hence, the observed pattern may relate to different pressures or habitat characteristics and availability in the tropics. Future work should deepen the analysis of seasonal bird-habitat associations at a broad scale along the southern GOM.

The Cancun radar is located south of the resort city with the same name, one of the major touristic destinations in Mexico, in a region where habitat loss has been driven by the growth and development of the tourism sector mainly along the coastline [36,72]. Coastal development in the eastern Yucatan has potentially affected the communities of migratory and resident bird species [73]. Consequently, greater bird densities farther away from the coast in spring may also be related to urban development. However, the proportion of urban cover within radar sample volumes was not important in explaining bird densities in our models, independently nor interacting with another predictor (Table S3). Nevertheless, our results suggest that bird densities increase with proportion of urban cover around the Cancun radar in spring and fall (Figures S6 and S7 respectively). Future work could explore in further depth how urbanization affects bird distributions during migration along the southern GOM.

Our results support our prediction that bird densities would be higher closer to the coast in the fall, but only for the Cancun radar. Thus, we have evidence that bird distributions in relation to distance to the coast are reversed compared to the north GOM around the northernmost radar in the Yucatan Peninsula. However, the coastline orientation around both radars in the Peninsula relative to the expected north-south axis of migration, is complex, and the available data did not allow estimating direction of migration movement, making it difficult to assess whether the observed patterns obey the expected movement of migration. Nevertheless, the Cancun radar is $\sim 50 \mathrm{~km}$ south of the north coast of the Peninsula, which is nearly perpendicular to the general north-south axis of Nearctic-Neotropical bird migration, similar to the north GOM. Hence, we consider that these characteristics make feasible the mirrored pattern of bird distributions between the north GOM and Cancun, and possible along all the north coast of the Peninsula. Contrastingly, the Sabancuy radar is located further south on the Peninsula, and the coastline within its domain runs southwest-northeast, extending then further north towards the Los Petenes and Ria Celestún Biosphere Reserves, which offer 282,857 ha and 81,482 ha of habitats such as mangroves and tropical deciduous forests, and border the west coast of the Peninsula [74,75]. Thus, we consider that the difference in coastline orientations around this radar and the north GOM may preclude the mirrored pattern, particularly if bird migration around Sabancuy follows the coast from or towards nearby protected areas. Future work could analyze bird distributions along the north coast of the Yucatan Peninsula, but currently there are no weather radars surveilling that area.

There is likely some daytime trans-Gulf arrivals of birds to the northern Yucatan coast during the fall season [29], when ALAN would not influence their stopover habitat selection. However, no studies have quantified the extent of daytime versus nighttime arrivals of trans-Gulf migrants in this region during the fall. Daytime landfall in the fall may help explain the weaker response of migrants to ALAN in Cancun and the difference between radars if daytime arrivals are more common at Cancun versus Sabancuy. Future studies, including ground surveys, would be valuable for assessing the distribution of migrating birds along the northern coast of the peninsula, and to test the bird distribution patterns in relation to the coast and ALAN reported here from weather radar observations.

Satellite measurements of night lights are affected by factors such as atmospheric conditions and satellite observation angles. Unless night-light measurements are made exactly at the zenith, radiance levels recorded for the same geographic extent may differ with the angle of satellite observation, for example by capturing different facades of buildings, or because light sources may be hidden by obstacles from a specific viewpoint [76,77]. Aerosols, water vapor, and ozone are some of the factors 
that influence the radiance scattered by the atmosphere, ultimately affecting the satellite-measured radiance from artificial lights [78]. The night-light data used for this research are monthly image composites averaging satellite observations that were subject to a series of algorithms to remove clouds and non-electric sources of lighting, and this averaging helps to minimize variations in night light measurements derived from different angles of satellite observation [79]. These monthly composites, however, do not account for atmospheric conditions and this is in fact a recognized area of improvement for such datasets [79]. Future investigations using atmospheric-corrected night-light data or improved models of night sky brightness distribution [80] may be able to elucidate more subtle patterns between bird distributions and ALAN.

Aeroecological analysis of Mexican weather radar data is challenging due to limited data availability and quality. The network of weather radars operated by the Mexican Weather Meteorological Service consists of 13 Doppler units with different technologies, in different status of operability, and in need of modernization [81]. The Sabancuy and Cancun radars were last updated in 1999 and 2009 respectively [81] and have been functional on and off in the last decade. Hence, the gaps in data for both radars and migration seasons. At the time of writing, only three of the thirteen radar stations operated by SMN seem operational (https://smn.conagua.gob.mx/es/observando-el-tiempo/radaresmeteorologicos). In addition to the sparsity in temporal coverage, we also found a limited geographic coverage within radars. For example, S-band weather radars from the NEXRAD network in the United States (US) detect birds in migration out to $120 \mathrm{~km}$, and birds at migration exodus out to between 50 and $100 \mathrm{~km}$ [82,83]. Here, we observed migration exodus consistently within $30 \mathrm{~km}$ from the C-band radars, reaching at most $50 \mathrm{~km}$ for birds aloft during migration in the middle of the night (e.g., Video S1). This, however, might be explained by the different wavelength that each radar network operates, and the greater atmospheric loss of C-band radars compared to S-band, derived from greater wavelength attenuation of the former $[84,85]$. Future efforts may use new developments to filter out precipitation from weather radar data [86], or a different processing approach [87], in order to salvage some of the precipitation-contaminated nights and increase the potential of the existing data to study bird migration around the southern GOM.

\section{Conclusions}

Geographic position in relation to bright lights and the coast is the major driver of broad-scale stopover distributions of nocturnally migrating birds along the Yucatan Peninsula coast and elsewhere. However, the responses of migrants to these drivers contrast in some important ways from migrants at more northern latitudes. Specifically, we present the first radar evidence of inconsistent broad-scale attraction of birds to stopover in bright areas during fall migration and consistent avoidance of bright areas during spring. These results contradict the pattern of broad-scale attraction of migrants to bright areas observed at more northern latitudes during both spring and fall, raising the question of how and why migrant response to light changes between seasons and between temperate and tropical latitudes. Furthermore, the pattern of coastal concentrations around Cancun during the fall, when birds arrive to the southern GOM after southbound flights, mirrors the pattern known from the northern GOM coast, when birds arrive to the coast in the spring. However, there are stronger coastal concentrations of migrants in the western Yucatan before crossing the GOM in spring and this is not mirrored in the US where there are higher densities inland before crossing the GOM in the fall. These results from the first broad-scale investigation of stopover distributions on the Yucatan peninsula of Mexico highlight the potential differences with other regions and need for increased study of bird stopover in the tropics.

Supplementary Materials: The following are available online at http://www.mdpi.com/2072-4292/12/3/395/s1. Table S1: Land cover classes aggregated from the 2010 North American Land Change Monitoring System; Table S2: Relative influence of all predictors included in the Boosted Regression Tree models for each season; Table S3: Interactions between predictors of bird densities by radar and season. Figure S1: Seasonal distribution of bird densities around each radar in relation to ALAN; Figure S2: Original and log-10 transformed intensity of artificial light at night around each radar; Figure S3: Pearson correlation coefficients of all predictors; Figures S4 to S7: Partial regression plots of all predictors of bird densities around Sabancuy and Cancun radars in spring and 
fall; Figure S8: Partial dependency plot for the most important interaction between predictors of bird densities around the Cancun radar in spring. Video S1: Animation of scans from the Cancun radar showing the evolution of reflectivity measures with the typical appearance of bird migration exodus.

Author Contributions: Conceptualization, S.A.C.-C.; methodology, J.J.B.; software, J.A.S.; formal analysis, S.A.C.-C. and J.J.B.; investigation, S.A.C.-C.; resources, S.A.C.-C., J.J.B., and E.B.C.; data curation, S.A.C.-C.; writing-original draft preparation, S.A.C.-C.; writing-review and editing, S.A.C.-C., E.B.C., J.A.S., and J.J.B.; visualization, S.A.C.-C.; supervision, J.J.B. and E.B.C.; funding acquisition, S.A.C.-C. and E.B.C. All authors have read and agreed to the published version of the manuscript.

Funding: At different stages of this work, S.A.C.-C. was supported by Fulbright-Garcia-Robles and CONACYT-COVEICyDET scholarships, by a Predoctoral Fellowship at the Smithsonian Conservation Biology Institute Migratory Bird Center, and by a University of Delaware Doctoral Fellowship.

Acknowledgments: Thanks to the Comisión Nacional del Agua (CONAGUA, Mexico) for providing radar data and Lucas Walls for assistance with screening radar data. Thanks to Armando Rodriguez-Dávila at CONAGUA for his support and expert advice regarding the network of Mexican weather radars and data acquisition. Thanks to José D. Cú-Vizcarra for confirming the nature of bat roosts near the Sabancuy radar.

Conflicts of Interest: The authors declare no conflict of interest. The funders had no role in the design of the study; in the collection, analyses, or interpretation of data; in the writing of the manuscript, or in the decision to publish the results.

\section{References}

1. Smolinsky, J.A.; Diehl, R.H.; Radzio, T.A.; Delaney, D.K.; Moore, F.R. Factors influencing the movement biology of migrant songbirds confronted with an ecological barrier. Behav. Ecol. Sociobiol. 2013, 67, 2041-2051. [CrossRef]

2. Alerstam, T. Detours in bird migration. J. Theor. Biol. 2001, 209, 319-331. [CrossRef] [PubMed]

3. Becciu, P.; Menz, M.H.M.; Aurbach, A.; Cabrera-Cruz, S.A.; Wainwright, C.E.; Scacco, M.; Ciach, M.; Pettersson, L.B.; Maggini, I.; Arroyo, G.M.; et al. Environmental effects on flying migrants revealed by radar. Ecography 2019, 42, 942-955. [CrossRef]

4. Larkin, R.P.; Frase, B.A. Circular paths of birds flying near a broadcasting tower in cloud. J. Comp. Psychol. 1988, 102, 90-93. [CrossRef]

5. Bruderer, B.; Peter, D.; Steuri, T. Behaviour of migrating birds exposed to X-band radar and a bright light beam. J. Exp. Biol. 1999, 202, 1015-1022. [PubMed]

6. Cabrera-Cruz, S.A.; Smolinsky, J.A.; McCarthy, K.P.; Buler, J.J. Urban areas affect flight altitudes of nocturnally migrating birds. J. Anim. Ecol. 2019, 88, 1873-1887. [CrossRef] [PubMed]

7. Van Doren, B.M.; Horton, K.G.; Dokter, A.M.; Klinck, H.; Elbin, S.B.; Farnsworth, A. High-intensity urban light installation dramatically alters nocturnal bird migration. Proc. Natl. Acad. Sci. USA 2017, 114, 11175-11180. [CrossRef]

8. Archibald, K.M.; Buler, J.J.; Smolinsky, J.A.; Smith, R.J. Migrating birds reorient toward land at dawn over the Great Lakes, USA. The Auk 2017, 134, 193-201. [CrossRef]

9. Diehl, R.H.; Larkin, R.P.; Black, J.E. Radar observations of bird migration over the Great Lakes. The Auk 2003, 120, 278-290. [CrossRef]

10. Buler, J.J.; Dawson, D.K. Radar analysis of fall bird migration stopover sites in the northeastern U.S. The Condor 2014, 116, 357-370. [CrossRef]

11. MMcLaren, J.D.; Buler, J.J.; Schreckengost, T.; Smolinsky, J.A.; Boone, M.; Loon, E.E.; van Dawson, D.K.; Walters, E.L. Artificial light at night confounds broad-scale habitat use by migrating birds. Ecol. Lett. 2018, 21, 356-364. [CrossRef] [PubMed]

12. LaFleur, J.M.; Buler, J.J.; Moore, F.R. Geographic position and landscape composition explain regional patterns of migrating landbird distributions during spring stopover along the northern coast of the Gulf of Mexico. Landsc. Ecol. 2016, 31, 1697-1709. [CrossRef]

13. Martínez, M.L.; Intralawan, A.; Vázquez, G.; Pérez-Maqueo, O.; Sutton, P.; Landgrave, R. The coasts of our world: Ecological, economic and social importance. Ecol. Econ. 2007, 63, 254-272. [CrossRef]

14. Imhoff, M.L.; Lawrence, W.T.; Elvidge, C.D.; Paul, T.; Levine, E.; Privalsky, M.V.; Brown, V. Using nighttime DMSP/OLS images of city lights to estimate the impact of urban land use on soil resources in the United States. Remote Sens. Environ. 1997, 59, 105-117. [CrossRef] 
15. Elvidge, C.D.; Tuttle, B.T.; Sutton, P.C.; Baugh, K.E.; Howard, A.T.; Milesi, C.; Bhaduri, B.; Nemani, R. Global distribution and density of constructed impervious surfaces. Sensors 2007, 7, 1962-1979. [CrossRef]

16. Longcore, T.; Rich, C. Ecological light pollution. Front. Ecol. Environ. 2004, 2, 191-198. [CrossRef]

17. Hölker, F.; Wolter, C.; Perkin, E.K.; Tockner, K. Light pollution as a biodiversity threat. Trends Ecol. Evol. 2010, 25, 681-682. [CrossRef]

18. Schroer, S.; Hölker, F. Impact of lighting on flora and fauna. In Handbook of Advanced Lighting Technology; Karlicek, R., Sun, C.-C., Zissis, G., Ma, R., Eds.; Springer International Publishing: Cham, Switzerland, 2016; pp. 957-989. ISBN 978-3-319-00295-8.

19. Dutcher, W. Bird Notes from Long Island, N. Y. The Auk 1884, 1, 174-179. [CrossRef]

20. Gauthreaux, S.A.; Belser, C.G. Effects of artificial night lighting on migrating birds. In Ecological Consequences of Artificial Night Lighting; Rich, C., Longcore, T., Eds.; Island Press: Washington, DC, USA, 2006; pp. 67-93. ISBN 1-55963-128-7.

21. Zuckerberg, B.; Fink, D.; La Sorte, F.A.; Hochachka, W.M.; Kelling, S. Novel seasonal land cover associations for eastern North American forest birds identified through dynamic species distribution modelling. Divers. Distrib. 2016, 22, 717-730. [CrossRef]

22. La Sorte, F.A.; Fink, D.; Buler, J.J.; Farnsworth, A.; Cabrera-Cruz, S.A. Seasonal associations with urban light pollution for nocturnally migrating bird populations. Glob Chang. Biol. 2017, 23, 4609-4619. [CrossRef]

23. Gauthreaux, S.A. Age-dependent orientation in migratory birds. In Avian Navigation. International Symposium on Avian Navigation (ISAN) Held at Tirrenia (Pisa), September 11-14, 1981; Papi, F., Wallraff, H.G., Eds.; Springer: Berlin, Germany, 1982; pp. 68-74.

24. Cabrera-Cruz, S.A.; Smolinsky, J.A.; Buler, J.J. Light pollution is greatest within migration passage areas for nocturnally-migrating birds around the world. Sci. Rep. 2018, 8, 3261. [CrossRef] [PubMed]

25. La Sorte, F.A.; Fink, D.; Hochachka, W.M.; Farnsworth, A.; Rodewald, A.D.; Rosenberg, K.V.; Sullivan, B.L.; Winkler, D.W.; Wood, C.; Kelling, S. The role of atmospheric conditions in the seasonal dynamics of North American migration flyways. J. Biogeogr. 2014, 41, 1685-1696. [CrossRef]

26. Dokter, A.M.; Farnsworth, A.; Fink, D.; Ruiz-Gutierrez, V.; Hochachka, W.M.; Sorte, F.A.L.; Robinson, O.J.; Rosenberg, K.V.; Kelling, S. Seasonal abundance and survival of North America's migratory avifauna determined by weather radar. Nat. Ecol. Evol. 2018, 2, 1603-1609. [CrossRef] [PubMed]

27. Horton, K.G.; Doren, B.M.V.; Sorte, F.A.L.; Cohen, E.B.; Clipp, H.L.; Buler, J.J.; Fink, D.; Kelly, J.F.; Farnsworth, A. Holding steady: Little change in intensity or timing of bird migration over the Gulf of Mexico. Glob. Chang. Biol. 2019, 25, 1106-1118. [CrossRef] [PubMed]

28. La Sorte, F.A.; Fink, D.; Hochachka, W.M.; Kelling, S. Convergence of broad-scale migration strategies in terrestrial birds. Proc. R. Soc. B 2016, 283. [CrossRef] [PubMed]

29. Deppe, J.L.; Ward, M.P.; Bolus, R.T.; Diehl, R.H.; Celis-Murillo, A.; Zenzal, T.J.; Moore, F.R.; Benson, T.J.; Smolinsky, J.A.; Schofield, L.N.; et al. Fat, weather, and date affect migratory songbirds' departure decisions, routes, and time it takes to cross the Gulf of Mexico. Proc. Natl. Acad. Sci. USA 2015, 112, E6331-E6338. [CrossRef]

30. Buler, J.J.; Moore, F.R. Migrant-habitat relationships during stopover along an ecological barrier: extrinsic constraints and conservation implications. J. Ornithol. 2011, 152, S101-S112. [CrossRef]

31. Loria, D.E.; Moore, F.R. Energy demands of migration on Red-eyed Vireos, Vireo olivaceus. Behav. Ecol. 1990, 1, 24-35. [CrossRef]

32. Buler, J.J.; Moore, F.R.; Woltmann, S. A multi-scale examination of stopover habitat use by birds. Ecology 2007, 88, 1789-1802. [CrossRef]

33. Seingier, G.; Espejel, I.; Fermán Almada, J.L. Cobertura vegetal y marginación en la costa mexicana. Investig. Ambiental. Cienc. Y Política Pública 2009, 1, 54-69.

34. Martinez, M.L.; Lithgow, D.; Vázquez, G.; Garcia-Franco, J.G. Diagnóstico de las necesidades y probabilidades de restauración en las dunas costeras de Quintana Roo. In Experiencias Mexicanas en la Restauración de los Ecosistemas; Ceccon, E., Martinez, C., Eds.; UNAM; CRIM; UAEM; CONABIO: Mexico City, Mexico, 2016; pp. 409-431. ISBN 978-607-02-8157-0.

35. Pérez-Villegas, G.; Carrascal, E. El desarrollo turístico en Cancún, Quintana Roo y sus consecuencias sobre la cubierta vegetal. Investig. Geográficas 2000, 43, 145-166. 
36. Ellis, E.A.; Romero-Montero, A.; Hernández-Gómez, I.U. Evaluación y Mapeo de los Determinantes de Deforestación en la Península Yucatán; United States Agency for International Development (USAID), The Nature Conservancy (TNC), Alianza México REDD+: Mexico City, Mexico, 2015.

37. Lynch, J.F. Distribution of overwintering Nearctic migrants in the Yucatan Peninsula, I: General patterns of occurrence. The Condor 1989, 91, 515-544. [CrossRef]

38. Lynch, J.F.; Whigham, D.F. The role of habitat disturbance in the ecology of overwintering migratory birds in the Yucatan Peninsula. In Proceedings of the Conservation of Neotropical Migratory Birds in Mexico; Maine Agricultural and Forest Experiment Station: Los Tuxtlas: Veracruz, Mexico, 1995; pp. 199-214.

39. Smith, A.L.; Ortiz, J.S.; Robertson, R.J. Distribution patterns of migrant and resident birds in successional forests of the Yucatan Peninsula, Mexico. Biotropica 2001, 33, 153-170. [CrossRef]

40. Amaya-Espinel, J.D.; Hostetler, M.E. The value of small forest fragments and urban tree canopy for Neotropical migrant birds during winter and migration seasons in Latin American countries: A systematic review. Landsc. Urban Plan. 2019, 190, 103592. [CrossRef]

41. Archer, J.-M.J.; Hostetler, M.E.; Acomb, G.; Blair, R. A systematic review of forest bird occurrence in North American forest fragments and the built environment. Landsc. Urban Plan. 2019, 185, 1-23. [CrossRef]

42. Cohen, E.B.; Barrow, W.C.; Buler, J.J.; Deppe, J.L.; Farnsworth, A.; Marra, P.P.; McWilliams, S.R.; Mehlman, D.W.; Wilson, R.R.; Woodrey, M.S.; et al. How do en route events around the Gulf of Mexico influence migratory landbird populations? The Condor 2017, 119, 327-343. [CrossRef]

43. Buler, J.J.; Diehl, R.H. Quantifying bird density during migratory stopover using weather surveillance radar. IEEE Trans. Geosci. Remote Sens. 2009, 47, 2741-2751. [CrossRef]

44. Larkin, R.P.; Diehl, R.H. Radar techniques for wildlife biology. In The Wildlife Techniques Manual: Volume 1: Research; Silvy, N.J., Ed.; Johns Hopkins University Press: Baltimore, MD, USA, 2012; Volume 1, pp. 319-335.

45. Lakshmanan, V.; Smith, T.; Stumpf, G.; Hondl, K. The Warning Decision Support System-Integrated Information. Weather Forecast. 2007, 22, 596-612. [CrossRef]

46. Åkesson, S.; Alerstam, T.; Hedenström, A. Flight initiation of nocturnal passerine migrants in relation to celestial orientation conditions at twilight. J. Avian Biol. 1996, 27, 95-102. [CrossRef]

47. Buler, J.J.; Barrow, W.C.; Boone, M.E.; Dawson, D.K.; Diehl, R.H.; Moore, F.R.; Randall, L.A.; Schreckengost, T.D.; Smolinsky, J.A. Linking animals aloft with the terrestrial landscape. In Aeroecology; Chilson, P.B., Frick, W.F., Kelly, J.F., Liechti, F., Eds.; Springer International Publishing: Cham, Switzerland, 2017; pp. 347-378. ISBN 978-3-319-68576-2.

48. UNIDATA. Integrated Data Viewer (IDV); UCAR/Unidata: Boulder, CO, USA, 2012.

49. Richardson, J.W. Timing of bird migration in relation to weather: updated reivew. In Bird migration; Spring-Verlag: Berlin, Germany, 1990; pp. 78-101.

50. Dokter, A.M.; Liechti, F.; Stark, H.; Delobbe, L.; Tabary, P.; Holleman, I. Bird migration flight altitudes studied by a network of operational weather radars. J. R. Soc. Interface 2011, 8, 30-43. [CrossRef]

51. Stepanian, P.M.; Horton, K.G.; Melnikov, V.M.; Zrnić, D.S.; Gauthreaux, S.A. Dual-polarization radar products for biological applications. Ecosphere 2016, 7, e01539. [CrossRef]

52. Jacobsen, E.; Lakshmanan, V. Inferring the state of the aerosphere from weather radar. In Aeroecology; Chilson, P.B., Frick, W.F., Kelly, J.F., Liechti, F., Eds.; Springer International Publishing: Cham, Switzerland, 2017; pp. 311-343. ISBN 978-3-319-68576-2.

53. Chilson, P.B.; Frick, W.F.; Stepanian, P.M.; Shipley, J.R.; Kunz, T.H.; Kelly, J.F. Estimating animal densities in the aerosphere using weather radar: To Z or not to Z? Ecosphere 2012, 3, art72. [CrossRef]

54. Njuguna, C. Rnightlights: Satellite Nightlight Data Extraction. 2018. Available online: https://cran.r-project. org/web/packages/Rnightlights/index.html (accessed on 10 September 2019).

55. Levin, N. The impact of seasonal changes on observed nighttime brightness from 2014 to 2015 monthly VIIRS DNB composites. Remote Sens. Environ. 2017, 193, 150-164. [CrossRef]

56. Falchi, F.; Cinzano, P.; Duriscoe, D.; Kyba, C.C.M.; Elvidge, C.D.; Baugh, K.; Portnov, B.A.; Rybnikova, N.A.; Furgoni, R. The new world atlas of artificial night sky brightness. Sci. Adv. 2016, 2, e1600377. [CrossRef] [PubMed]

57. Canada Centre for Remote Sensing (CCRS); Canada Centre for Mapping and Earth Observation (CCMEO); Natural Resources Canada (NRCan); Comisión Nacional para el Conocimiento y Uso de la Biodiversidad (CONABIO); Comisión Nacional Forestal (CONAFOR); Insituto Nacional de Estadística y Geografía (INEGI). U.S. Geological Survey (USGS) North American Land Change Monitoring System (NALCMS) Collection. 
2017. Available online: http://www.cec.org/tools-and-resources/map-files/land-cover-2010-landsat-30m (accessed on 25 October 2019).

58. Ellis, E.A.; Gomez, U.H.; Romero-Montero, J.A. Los procesos y causas del cambio en la cobertura forestal de la Península Yucatán, México. Rev. Ecosistemas 2017, 26, 101-111. [CrossRef]

59. Hansen, M.C.; Potapov, P.V.; Moore, R.; Hancher, M.; Turubanova, S.A.; Tyukavina, A.; Thau, D.; Stehman, S.V.; Goetz, S.J.; Loveland, T.R.; et al. High-Resolution Global Maps of 21st-century forest cover change. Science 2013, 342, 850-853. [CrossRef] [PubMed]

60. Mattiuzzi, M.; Verbesselt, J.; Hengl, T.; Klisch, A.; Stevens, F.; Mosher, S.; Evans, B.; Lobo, A.; Hufkens, K.; Detsch, F. MODIS: Acquisition and Processing of MODIS Products. 2019. Available online: https://cran.rproject.org/web/packages/MODIS/index.html (accessed on 25 October 2019).

61. Elith, J.; Leathwick, J.R.; Hastie, T. A working guide to boosted regression trees. J. Anim. Ecol. 2008, 77, 802-813. [CrossRef]

62. De'Ath, G. Boosted trees for ecological modeling and prediction. Ecology 2007, 88, 243-251. [CrossRef]

63. R Development Core Team. R: A Language and Environment for Statistical Computing; R Foundation for Statistical Computing: Vienna, Austria, 2017.

64. Hijmans, R.J.; Phillips, S.; Leathwick, J.R.; Elith, J. Package “dismo". Species distribution modeling. 2015. Available online: https://cran.r-project.org/web/packages/dismo/index.html (accessed on 25 October 2019).

65. Dormann, C.F.; Elith, J.; Bacher, S.; Buchmann, C.; Carl, G.; Carré, G.; Marquéz, J.R.G.; Gruber, B.; Lafourcade, B.; Leitão, P.J.; et al. Collinearity: a review of methods to deal with it and a simulation study evaluating their performance. Ecography 2013, 36, 27-46. [CrossRef]

66. Hutto, R.L. Habitat selection by nonbreeding, migratory land birds. In Habitat Selection in Birds; Cody, M.L., Ed.; Academic Press, Inc.: Orlando, FL, USA, 1985; pp. 455-476.

67. Chernetsov, N. Habitat selection by nocturnal passerine migrants en route: mechanisms and results. J. Ornithol. 2006, 147, 185-191. [CrossRef]

68. Deppe, J.L.; Rotenberry, J.T. Scale-dependent habitat use by fall migratory birds: vegetation structure, floristics, and geography. Ecol. Monogr. 2008, 78, 461-487. [CrossRef]

69. Loss, S.R.; Will, T.; Marra, P.P. Direct mortality of birds from anthropogenic causes. Annu. Rev. Ecol. Evol. Syst. 2015, 46, 99-120. [CrossRef]

70. Loss, S.R.; Lao, S.; Eckles, J.W.; Anderson, A.W.; Blair, R.B.; Turner, R.J. Factors influencing bird-building collisions in the downtown area of a major North American city. PLoS ONE 2019, 14, e0224164. [CrossRef]

71. Gómez, C.; Bayly, N.J.; Norris, D.R.; Mackenzie, S.A.; Rosenberg, K.V.; Taylor, P.D.; Hobson, K.A.; Cadena, C.D. Fuel loads acquired at a stopover site influence the pace of intercontinental migration in a boreal songbird. Sci. Rep. 2017, 7, 1-11. [CrossRef]

72. Ellis, E.A.; Romero Montero, J.A.; Hernández Gómez, I.U. Deforestation processes in the state of Quintana Roo, Mexico: The role of land use and community forestry. Trop. Conserv. Sci. 2017, 10, 1940082917697259. [CrossRef]

73. Raymundo-Sanchez, A.A. Avian community structure and diversity in relation to coastal development in the Sian Ka'an Biosphere Reserve and Riviera Maya, Quintana Roo, Mexico. Master's Thesis, University of Tennessee, Knoxville, TN, USA, 2010.

74. CONANP. Programa de Conservación y Manejo Reserva de la Biosfera Los Petenes, Mexico, 1st ed.; Comisión Nacional de Áreas Naturales Protegidas: Mexico City, Mexico, 2006; ISBN 968-817-813-6.

75. SEMARNAT. Programa de Manejo Reserva de la Biosfera Ria Celestun, Mexico; Secretaria de Medio Ambiente y Recursos Naturales: Mexico City, Mexico, 2000.

76. Li, X.; Ma, R.; Zhang, Q.; Li, D.; Liu, S.; He, T.; Zhao, L. Anisotropic characteristic of artificial light at night-Systematic investigation with VIIRS DNB multi-temporal observations. Remote Sens. Environ. 2019, 233, 111357. [CrossRef]

77. Levin, N.; Kyba, C.C.M.; Zhang, Q.; Sánchez de Miguel, A.; Román, M.O.; Li, X.; Portnov, B.A.; Molthan, A.L.; Jechow, A.; Miller, S.D.; et al. Remote sensing of night lights: A review and an outlook for the future. Remote Sens. Environ. 2020, 237, 111443. [CrossRef]

78. Román, M.O.; Wang, Z.; Sun, Q.; Kalb, V.; Miller, S.D.; Molthan, A.; Schultz, L.; Bell, J.; Stokes, E.C.; Pandey, B.; et al. NASA's Black Marble nighttime lights product suite. Remote Sens. Environ. 2018, 210, 113-143. [CrossRef] 
79. Elvidge, C.D.; Baugh, K.; Zhizhin, M.; Hsu, F.C.; Ghosh, T. VIIRS night-time lights. Int. J. Remote Sens. 2017, 38, 5860-5879. [CrossRef]

80. Kocifaj, M.; Bará, S. Two-index model for characterizing site-specific night sky brightness patterns. Mon. Not. R. Astron. Soc. 2019, 490, 1953-1960. [CrossRef]

81. Strmiska, I. Modernización del Servicio Meteorológico Nacional_Fortalecimiento y desarrollo estratégico de la Red Nacional de Radares Meteorológicos; Informe OMM/PREMIA; CONAGUA, OMM: Mexico City, Mexico, 2010; p. 45.

82. Gauthreaux, S.A.; Belser, C.G. Displays of bird movements on the WSR-88D: Patterns and quantification. Wea. Forecast. 1998, 13, 453-464. [CrossRef]

83. Gauthreaux, S.A.; Belser, C.G. Radar ornithology and biological conservation. The Auk 2003, 120, $266-277$. [CrossRef]

84. Ryzhkov, A.V.; Zrnic, D. Radar polarimetry at S, C, and X bands: Comparative analysis and operational implications. In Proceedings of the 32nd Conference on Radar Meteorology; American Meteorological Society: Albuquerque, NM, USA, 2005; p. 6.

85. Johnson, B.C.; Brandes, E.A. Attenuation of a 5-Cm wavelength radar signal in the Lahoma-Orienta storms. J. Atmos. Ocean. Technol. 1987, 4, 512-517. [CrossRef]

86. Lin, T.-Y.; Winner, K.; Bernstein, G.; Mittal, A.; Dokter, A.M.; Horton, K.G.; Nilsson, C.; Doren, B.M.V.; Farnsworth, A.; Sorte, F.A.L.; et al. MistNet: Measuring historical bird migration in the US using archived weather radar data and convolutional neural networks. Methods Ecol. Evol. 2019, 10, 1908-1922. [CrossRef]

87. Dokter, A.M.; Desmet, P.; Spaaks, J.H.; Hoey, S.; van Veen, L.; Verlinden, L.; Nilsson, C.; Haase, G.; Leijnse, H.; Farnsworth, A.; et al. bioRad: biological analysis and visualization of weather radar data. Ecography 2019, 42, 852-860. [CrossRef]

(C) 2020 by the authors. Licensee MDPI, Basel, Switzerland. This article is an open access article distributed under the terms and conditions of the Creative Commons Attribution (CC BY) license (http://creativecommons.org/licenses/by/4.0/). 